\title{
Highly Diastereoselective Heterogeneously-Catalyzed Hydrogenation of Enamines for the Synthesis of Chiral $\beta$ - Amino Acid Derivatives
}

\section{(Supporting Information)}

Norihiro Ikemoto*, David M. Tellers*, Spencer D. Dreher, Jinchu Liu, Angie Huang, Nelo Rivera*, Eugenia Njolito, Yi Hsiao, J. Christopher McWilliams, J. Michael Williams, Joseph D. Armstrong, III, Yongkui Sun, David J. Mathre, Edward J. J. Grabowski and Richard D. Tillyer

Department of Process Research and the Catalysis and Reaction Discovery and Development Lab (CRDD), Merck and Co., Inc., PO Box 2000, Rahway, NJ 07065-0900

Suppl 1. Z/E Isomeric Ratios and UV and ${ }^{1} \mathrm{H}-\mathrm{NMR}$ Data.

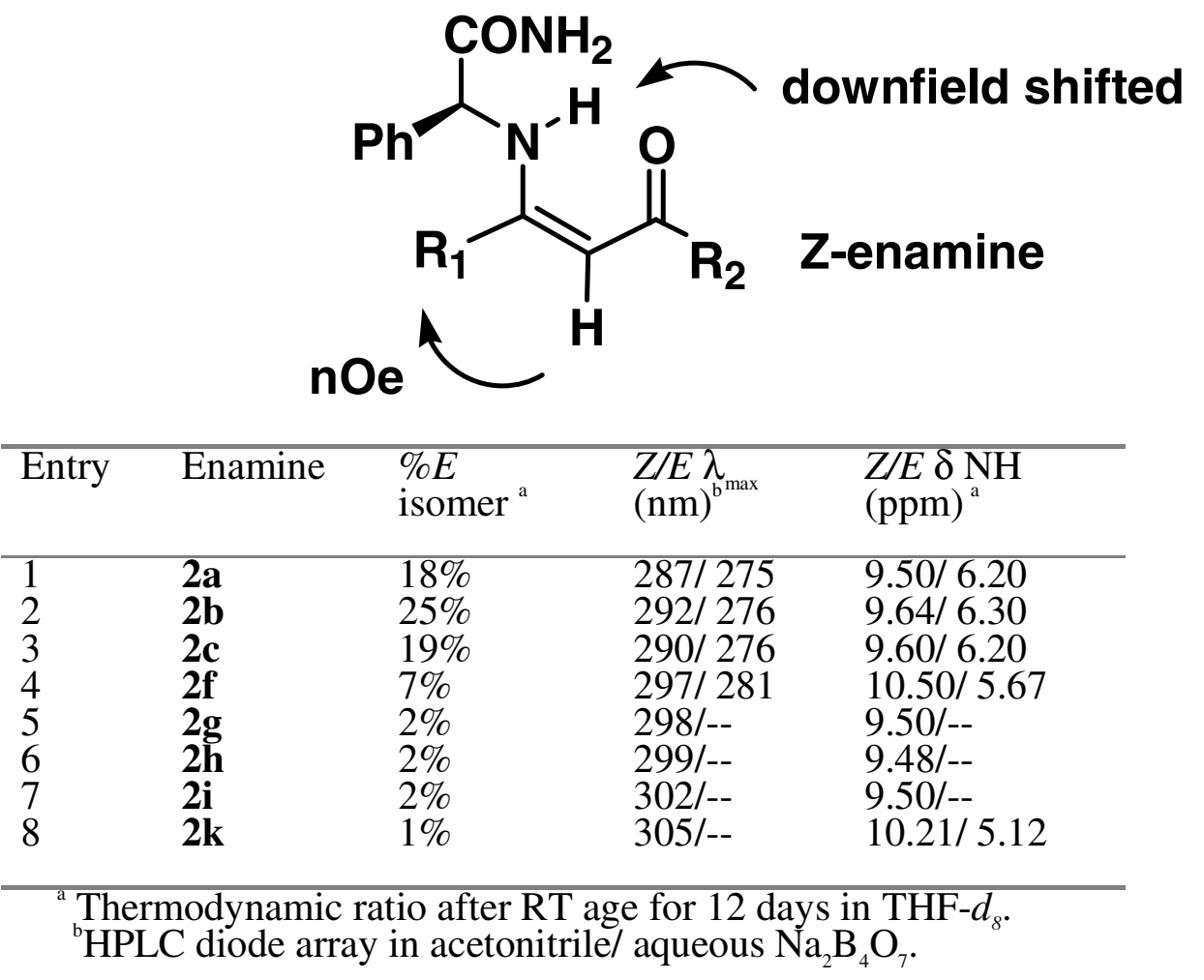




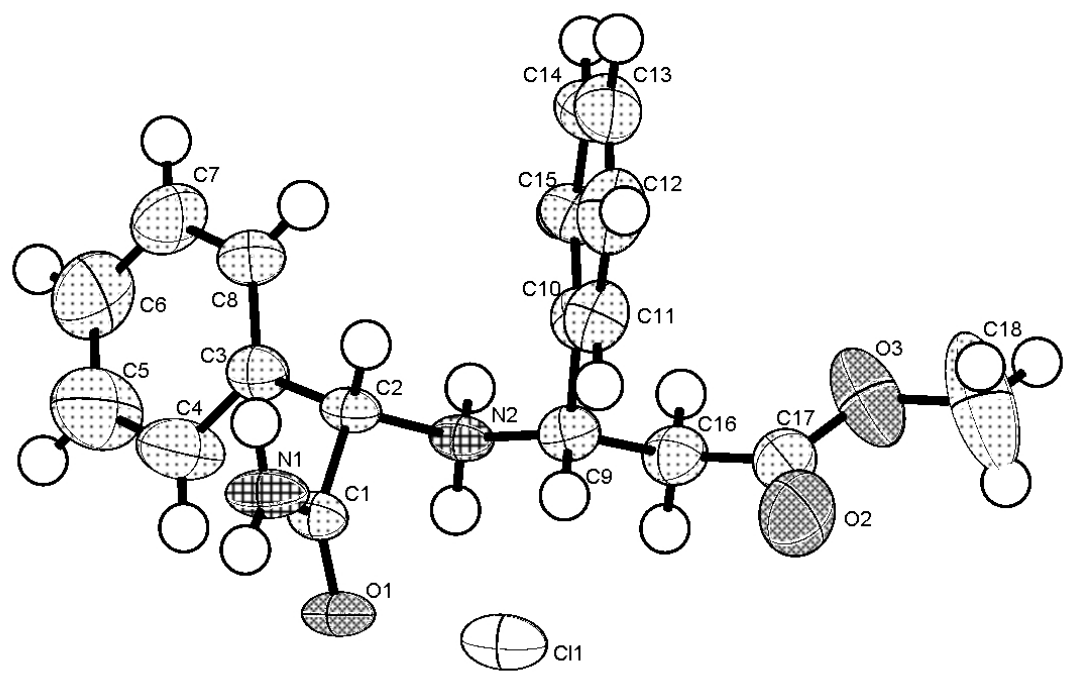

Suppl 2. X-ray Structure of Phenyl PGA-Aminoester 3g.(HCl salt).

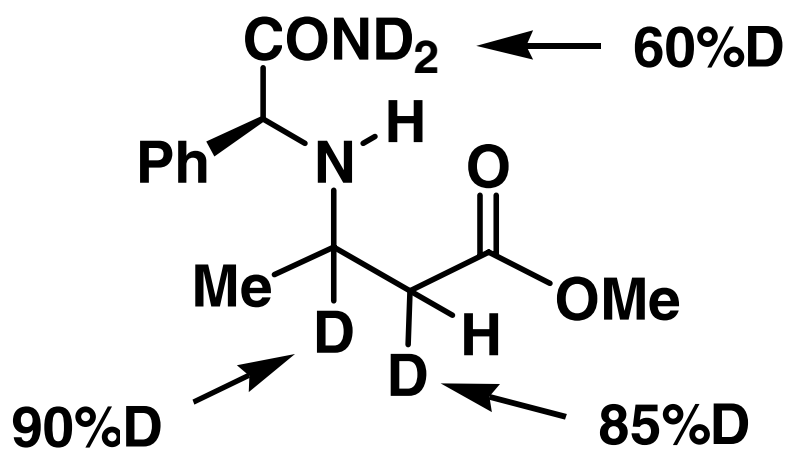

Suppl 3. Hydrogenation of $\mathbf{2 a}$ with $\mathrm{D}_{2}$ and $\mathrm{PtO}_{2}$ in THF- $d_{8}$

Experimental: The acid-washed catalyst $(25 \mathrm{mg}$ ) was placed under deuterium gas (90 psig) in THF- $d_{8}(0.75 \mathrm{~mL})$. After $3 \mathrm{~h}$, the solution was brought into a glove box and the black, finely dispersed catalyst was isolated by filtration and then dried under reduced pressure for $5 \mathrm{~h}$. This pre-reduced catalyst $(4.6 \mathrm{mg})$ was transferred to a THF- $d_{8}$ solution $(0.75 \mathrm{~mL})$ containing $\mathbf{2 a}$ and the resulting heterogeneous slurry placed under deuterium gas (90 psig) for $5 \mathrm{~h}$. The solution was vented, filtered and the filtrate concentrated under reduced pressure. The resulting light yellow oil was dissolved in benzene- $d_{6}$ and a single pulse ${ }^{1} \mathrm{H}-\mathrm{NMR}$ spectrum was acquired. Integration showed $90.4 \%$ deuterium incorporation into the $\alpha$ and $\beta$ positions of $\mathbf{3 a}$. 


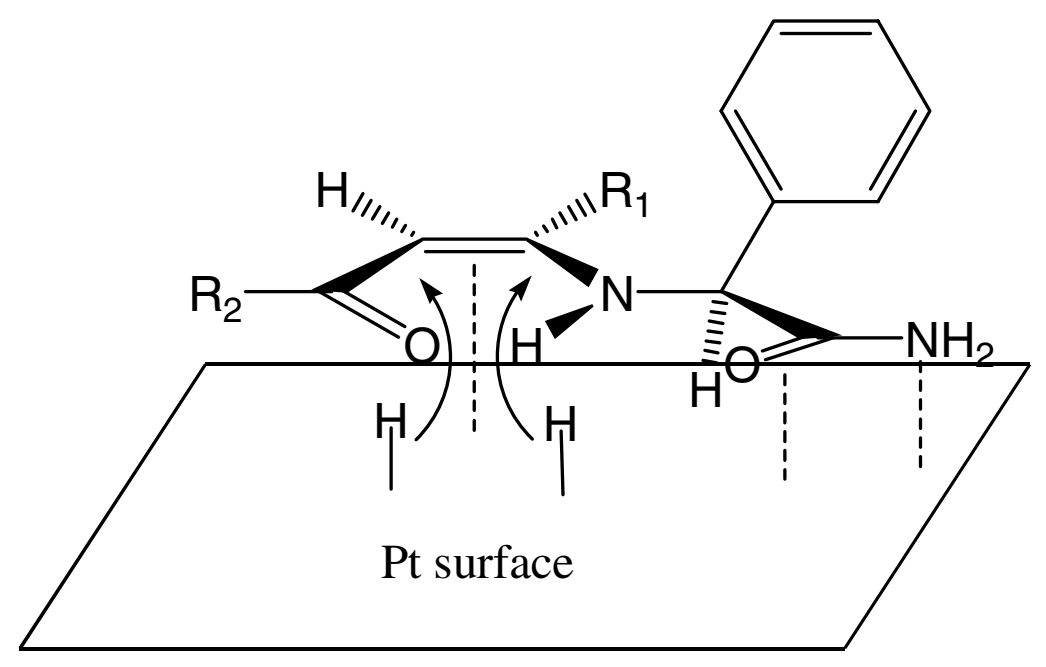

Suppl 4. Model for the diastereofacial selective binding and hydrogenation on the platinum catalyst.

\section{EXPERIMENTALS}

General: $(S)$-PGA was purchased from DSM and Omegachem, Inc. $\mathrm{PtO}_{2}$ (lot\#323760) was purchased from Englehard. Pressure reaction vessels used for the hydrogenation were purchased from Andrews Glass Company. The THF and $\mathrm{MeOH}$ (OmniSolv grade) used for the hydrogenations were obtained from EMD Chemicals and used without further purification.

\section{Z-PGA-Enamines:}

1) Methyl (2Z)-3-\{[(1S)-2-amino-2-oxo-1phenylethyl]amino\}but-2-enoate (1a). Methyl acetoacetate (2.0 g, $17.2 \mathrm{mmol})$ and $(S)$-PGA $(2.58 \mathrm{~g}, 17.2 \mathrm{mmol})$ were dissolved in $\mathrm{MeOH} 200 \mathrm{~mL})$ at $40{ }^{\circ} \mathrm{C}$ and acetic acid $(0.5 \mathrm{~mL}, 8.6 \mathrm{mmol})$ was

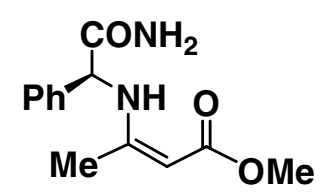
added. Solids formed after $1 \mathrm{~h}$ at $40{ }^{\circ} \mathrm{C}$. The mixture was cooled to $4{ }^{\circ} \mathrm{C}$ and filtered. The solids were rinsed with cold $\mathrm{MeOH}$ and dried to afford the enamine $(3.3 \mathrm{~g}, 77 \%$ yield). $[\alpha]_{\mathrm{D}}{ }^{25}=-92$ (c 0.44, DCM). $\mathrm{mp}=159^{\circ} \mathrm{C} .{ }^{1} \mathrm{H}-\mathrm{NMR}$ (DMSO-d $\left.\mathrm{d}_{6}, 400 \mathrm{MHz}\right): \delta 9.46$ $(\mathrm{d}, J=8 \mathrm{~Hz}, 1 \mathrm{H}), 7.70(\mathrm{br}, 1 \mathrm{H}), 7.37(\mathrm{~m}, 4 \mathrm{H}), 7.28(\mathrm{~m}, 2 \mathrm{H}), 5.19(\mathrm{~d}, J=8 \mathrm{~Hz}, 1 \mathrm{H}), 4.44$ (s, 1H), $3.52(\mathrm{~s}, 3 \mathrm{H}), 1.73(\mathrm{~s}, 3 \mathrm{H})$. NOE enhancement: $4.5 \% \mathrm{C}-4$ methyl group upon irradiation of the olefinic hydrogen. ${ }^{13} \mathrm{C}-\mathrm{NMR}$ (DMSO- $\mathrm{d}_{6}, 100 \mathrm{MHz}$ ): $\delta 171.2,169.5$, 160.1, 139.8, 128.7, 127.8, 126.4, 83.1, 59.0, 49.6, 19.4. Anal. Calcd for $\mathrm{C}_{13} \mathrm{H}_{16} \mathrm{~N}_{2} \mathrm{O}_{3}$ : C, 62.89; H, 6.50; N, 11.28; O, 19.33. Found: C, 62.60; H, 6.56; N, 11.21; O, 19.32.

2) Methyl (2Z)-3-\{[(1S)-2-amino-2-oxo-1-phenylethyl $]$ amino $\}-4-$ methylpent-2-enoate (2b). Methyl isobutyryl acetate (7.59 g, 50.0

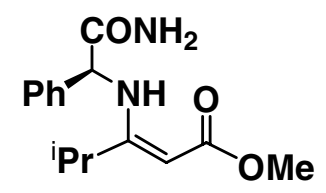


mmol) and (S)-PGA (7.51 g, $50.0 \mathrm{mmol})$ were mixed in IPA $(40 \mathrm{~mL})$ at $40^{\circ} \mathrm{C}$ and acetic acid $(1.43 \mathrm{~mL}, 25 \mathrm{mmol})$ was added. A slurry formed quickly. The mixture was stirred overnight at $40{ }^{\circ} \mathrm{C}$, cooled to $3{ }^{\circ} \mathrm{C}$ then was filtered. The solids were rinsed with IPA and dried to afford the enamine as a white solid (11.6 g, 84\% yield). $[\alpha]_{\mathrm{D}}{ }^{25}=-57$ (c 0.58 , DCM). $\mathrm{mp}=170{ }^{\circ} \mathrm{C} .{ }^{1} \mathrm{H}-\mathrm{NMR}\left(\mathrm{DMSO}_{\mathrm{d}}, 400 \mathrm{MHz}\right): \delta 9.55(\mathrm{~d}, J=8 \mathrm{~Hz}, 1 \mathrm{H}), 7.76(\mathrm{~s}$, $1 \mathrm{H}), 7.40(\mathrm{~m}, 4 \mathrm{H}), 7.30(\mathrm{~m}, 2 \mathrm{H}), 5.29(\mathrm{~d}, J=8 \mathrm{~Hz}, 1 \mathrm{H}), 4.48(\mathrm{~s}, 1 \mathrm{H}), 3.54(\mathrm{~s}, 3 \mathrm{H}), 2.44$ $(\mathrm{m}, 1 \mathrm{H}), 1.08(\mathrm{~d}, J=7 \mathrm{~Hz}, 3 \mathrm{H}), 0.78(\mathrm{~d}, J=7 \mathrm{~Hz}, 3 \mathrm{H})$. nOe enhancement: $2.5 \%$ and $3.5 \%$ for the i-Pr methyl groups upon irradiation of the olefinic hydrogen. ${ }^{13} \mathrm{C}-\mathrm{NMR}$ (DMSO-d ${ }_{6}, 100 \mathrm{MHz}$ ): $\delta 171.5,170.5,170.2,140.6,129.0,128.1,126.6,79.2,58.5$, 49.9, 29.2, 22.4, 21.1. Anal. Calcd for $\mathrm{C}_{15} \mathrm{H}_{20} \mathrm{~N}_{2} \mathrm{O}_{3}: \mathrm{C}, 65.20 ; \mathrm{H}, 7.30 ; \mathrm{N}, 10.14 ; \mathrm{O}, 17.37$. Found: C, 62.82; H, 7.22; N, 9.71; O, 17.25.

3) Methyl (2Z)-3-\{[(1S)-2-amino-2-oxo-1-phenylethyl]amino\}-4phenylbut-2-enoate (2c). Methyl 3-oxo-4-phenylbutanoate (1.76 g, $9.16 \mathrm{mmol})$ and $(S)$-PGA $(1.38 \mathrm{~g}, 9.16 \mathrm{mmol})$ were mixed in IPA (18 $\mathrm{mL})$ and acetic acid $(0.26 \mathrm{~mL}, 4.6 \mathrm{mmol})$ and stirred $18 \mathrm{~h}$ over a 50

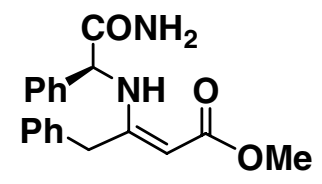
${ }^{\circ} \mathrm{C}$ bath. The resulting slurry was cooled and filtered. The solids were rinsed with cold $\mathrm{MeOH}$ and dried to afford the enamine $\left(2.20 \mathrm{~g}, 74 \%\right.$ yield). $\left[\alpha_{\mathrm{D}}\right]^{25}=-63$ (c $\left.0.40, \mathrm{DCM}\right)$. $\mathrm{mp}=169{ }^{\circ} \mathrm{C} .{ }^{1} \mathrm{H}-\mathrm{NMR}\left(\right.$ DMSO-d $\left._{6}, 400 \mathrm{MHz}\right): \delta 9.46(\mathrm{~d}, J=8 \mathrm{~Hz}, 1 \mathrm{H}), 7.71(\mathrm{~s}, 1 \mathrm{H})$, $7.34(\mathrm{~d}, 4 \mathrm{H}), 7.26(\mathrm{~m}, 4 \mathrm{H}), 7.20(\mathrm{~m}, 1 \mathrm{H}), 7.08(\mathrm{~d}, 2 \mathrm{H}), 5.10(\mathrm{~d}, J=8 \mathrm{~Hz}, 1 \mathrm{H}), 4.30(\mathrm{~s}$, $1 \mathrm{H}), 3.50(\mathrm{~s}, 3 \mathrm{H}), 3.32(\mathrm{q}, 2 \mathrm{H})$. nOe enhancement: $3.5 \%$ allylic hydrogens upon irradiation of the olefinic hydrogen. ${ }^{13} \mathrm{C}-\mathrm{NMR}$ (DMSO- $\mathrm{d}_{6}, 100 \mathrm{MHz}$ ): $\delta$ 170.8, 169.4, 161.7, 139.9, 136.3, 128.7, 128.6, 128.6, 127.8, 126.7, 126.3, 84.6, 58.6, 49.7, 37.9. Anal. Calcd for $\mathrm{C}_{19} \mathrm{H}_{20} \mathrm{~N}_{2} \mathrm{O}_{3}$ : C, 70.35; H, 6.21; N, 8.64; O, 14.80. Found: C, 70.31; H, 6.30; $\mathrm{N}, 8.98 ; \mathrm{O}, 14.49$.

4) (2S)-2-\{[(1Z)-1-benzyl-3-oxo-3-piperidin-1-ylprop-1-en-1yl]amino\}-2-phenylacetamide (2f). 4-Oxo-1-phenyl-4-piperidin-1ylbutan-2-one (13.8 g, $56.0 \mathrm{mmol})$ and $(S)$-PGA $(8.42 \mathrm{~g}, 56.0 \mathrm{mmol})$ were stirred in $\mathrm{MeOH}(70 \mathrm{~mL})$ with acetic acid $(1.6 \mathrm{~mL}, 28 \mathrm{mmol}) 3$ days at $40{ }^{\circ} \mathrm{C}$. The mixture was concentrated and the residue was

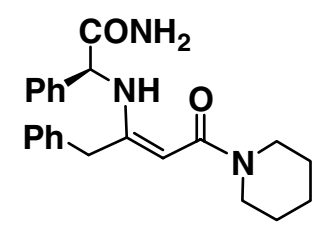
purified by flash chromatography (80-100\% EtOAc/ hexane) and then was crystallized (EtOAc/ hexane) to afford the enamine $(7.4 \mathrm{~g}, 35 \%) \cdot[\alpha]_{\mathrm{D}}^{25}=-86(\mathrm{c} 0.44, \mathrm{MeOH}) . \mathrm{mp}=$ $155{ }^{\circ} \mathrm{C}$. ${ }^{1} \mathrm{H}-\mathrm{NMR}$ (DMSO-d $6,400 \mathrm{MHz}$ ): $\delta 10.23(\mathrm{~d}, J=9 \mathrm{~Hz}, 1 \mathrm{H}), 7.60(\mathrm{br}, 1 \mathrm{H}), 7.29$ $(\mathrm{m}, 9 \mathrm{H}), 7.19(\mathrm{~m}, 1 \mathrm{H}), 7.10(\mathrm{br}, 1 \mathrm{H}), 4.99(\mathrm{~d}, J=9 \mathrm{~Hz}, 1 \mathrm{H}), 4.81(\mathrm{~s}, 1 \mathrm{H}), 3.32-3.35(\mathrm{~m}$, $6 \mathrm{H}), 2.49(\mathrm{~m}, 2 \mathrm{H}), 1.41(\mathrm{~m}, 4 \mathrm{H})$. nOe enhancement: $4 \%$ allylic hydrogens upon irratidation of the olefinic hydrogen. ${ }^{13} \mathrm{C}-\mathrm{NMR}$ (DMSO- $\mathrm{d}_{6}, 100 \mathrm{MHz}$ ): $\delta 171.3,168.3$, 158.2, 140.3, 137.3, 128.4, 128.3, 127.5, 126.5, 126.4, 85.1, 58.9, 38.6, 25.8, 24.3. Anal. Calcd for $\mathrm{C}_{23} \mathrm{H}_{27} \mathrm{~N}_{3} \mathrm{O}_{2}$ : C, 73.18; H, 7.21; N, 11.13; O, 8.48. Found: C, 73.19; H, 7.33; $\mathrm{N}, 11.12 ; \mathrm{O}, 8.54$.

5) (2Z)-3-\{[(1S)-2-amino-2-oxo-1-phenylethyl]amino\}-4phenylbut-2-enamide (2e). 3-Oxo-4-phenylbutanamide (1.85 g, 10.4 $\mathrm{mmol})$ and $(S)$-PGA $(1.56 \mathrm{~g}, 10.4 \mathrm{mmol})$ were stirred in $\mathrm{MeOH}(18$ $\mathrm{mL})$ with acetic acid $(0.30 \mathrm{~mL}, 5.2 \mathrm{mmol}) 4$ days at $40{ }^{\circ} \mathrm{C}$. The mixture was diluted with MTBE, washed with sat'd sodium bicarbonate, dried (MgSO4)

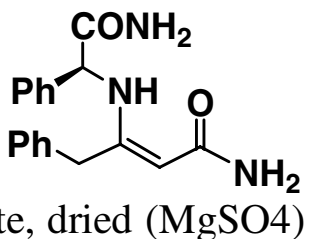


and concentrated. The residue was purified by flash chromatography (50-100\% EtOAc/hexane) and then crystallized (EtOAc/ hexane) to afford the enamine (0.63 g, 20\%). $[\alpha]_{\mathrm{D}}{ }^{25}=+9$ (c $\left.0.18, \mathrm{DCM}\right) . \mathrm{mp}=188^{\circ} \mathrm{C} .{ }^{1} \mathrm{H}-\mathrm{NMR}\left(\mathrm{DMSO}-\mathrm{d}_{6}, 400 \mathrm{MHz}\right): \delta 9.89$ $(\mathrm{d}, J=8.8 \mathrm{~Hz}, 1 \mathrm{H}), 7.61(\mathrm{~s}, 1 \mathrm{H}), 7.33(\mathrm{~m}, 4 \mathrm{H}), 7.28(\mathrm{~d}, J=7 \mathrm{~Hz}, 3 \mathrm{H}), 7.21(\mathrm{~m}, 1 \mathrm{H}), 7.15$ (d, $7 \mathrm{~Hz}, 2 \mathrm{H}), 7.10(\mathrm{~s}, 1 \mathrm{H}), 6.6(\mathrm{br}, 1 \mathrm{H}), 6.1(\mathrm{br}, 1 \mathrm{H}), 5.01(\mathrm{~d}, J=8.8 \mathrm{~Hz}, 1 \mathrm{H}), 4.37$ (s, $1 \mathrm{H}), 3.27(\mathrm{q}, 2 \mathrm{H})$. nOe enhancement: $4.7 \%$ allylic hydrogens upon irradiation of the olefinic hydrogen. ${ }^{13} \mathrm{C}-\mathrm{NMR}$ (DMSO- $\mathrm{d}_{6}, 100 \mathrm{MHz}$ ): $\delta$ 171.7, 171.4, 157.2, 140.5, 137.2, 128.5, 128.4, 127.4, 126.4, 126.4, 89.4, 58.9, 38.1. Anal. Calcd for $\mathrm{C}_{18} \mathrm{H}_{19} \mathrm{~N}_{3} \mathrm{O}_{2}$ : C, 69.88; H, 6.19; N, 13.58. Found: C, 69.51; H, 6.10; N, 13.48.

6) Methyl 2-\{[(1S)-2-amino-2-oxo-1-phenylethyl $]$ amino $\}$ cyclohex-1ene-1-carboxylate (2d). Methyl cyclohexane-2-carboxylate (8.22 g, $50.0 \mathrm{mmol})$ and $(S)$-PGA $(150.7 .51 \mathrm{~g}, 50.0 \mathrm{mmol})$ were dissolved in $\mathrm{MeOH}(40 \mathrm{~mL})$ at $40{ }^{\circ} \mathrm{C}$ and acetic acid $(1.43 \mathrm{~mL}, 25 \mathrm{mmol})$ was added. Solids formed in a few minutes. The mixture was stirred $1 \mathrm{~h}$ at

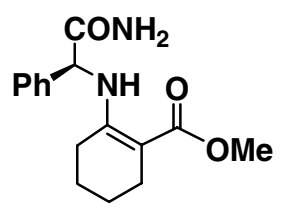
$40{ }^{\circ} \mathrm{C}$ then was cooled to $3{ }^{\circ} \mathrm{C}$ and was filtered. The solids were rinsed with $\mathrm{MeOH}(10$ $\mathrm{mL})$ and dried in a vacuum oven to afford the enamine as a white solid $(12.5 \mathrm{~g}, 87 \%$ yield). $[\alpha]_{\mathrm{D}}{ }^{25}=-177$ (c $\left.0.48, \mathrm{MeOH}\right) . \mathrm{mp}=201{ }^{\circ} \mathrm{C} .{ }^{1} \mathrm{H}-\mathrm{NMR}\left(\mathrm{DMSO}_{\mathrm{d}}, 400 \mathrm{MHz}\right): \delta$ $9.73(\mathrm{~d}, J=7.9 \mathrm{~Hz}, 1 \mathrm{H}), 7.67(\mathrm{~s}, 1 \mathrm{H}), 7.27(\mathrm{~m}, 4 \mathrm{H}), 7.27(\mathrm{~m}, 1 \mathrm{H}), 7.21(\mathrm{~s}, 1 \mathrm{H}), 5.18(\mathrm{~d}, J$ $=7.9 \mathrm{~Hz}, 1 \mathrm{H}), 3.58(\mathrm{~s}, 3 \mathrm{H}), 2.29(\mathrm{~m}, 1 \mathrm{H}), 2.16(\mathrm{~m}, 2 \mathrm{H}), 1.90(\mathrm{~m}, 1 \mathrm{H}), 1.49(\mathrm{~m}, 1 \mathrm{H}), 1.40$ (m, 3H). ${ }^{13} \mathrm{C}-\mathrm{NMR}$ (DMSO-d $\mathrm{d}_{6}, 100 \mathrm{MHz}$ ): $\delta$ 171.4, 169.6, 157.3, 140.2, 128.5, 127.5, 126.3, 90.0, 58.5, 50.1, 26.1, 23.5, 22.1, 21.6. Anal. Calcd for $\mathrm{C}_{16} \mathrm{H}_{20} \mathrm{~N}_{2} \mathrm{O}_{3}$ : C, 66.65; H, 6.99; N, 9.72; O, 16.65. Found: C, 66.30; H, 7.00; N, 9.64; O, 16.66 .

7) Methyl (2Z)-3-\{[(1S)-2-amino-2-oxo-1-phenylethyl $]$ amino\}-3phenylacrylate (2g). Methyl 3-oxo-3-phenylpropanoate $(20.2 \mathrm{~g}, 114$ $\mathrm{mmol})$ and $(S)$-PGA $(17.0 \mathrm{~g}, 114 \mathrm{mmol})$ were added to $\mathrm{MeOH}(60 \mathrm{~mL})$ with acetic acid $(3.25 \mathrm{~mL}, 57 \mathrm{mmol})$ and stirred 4 days over a $40{ }^{\circ} \mathrm{C}$ bath. The mixture was concentrated and the residue was purified by

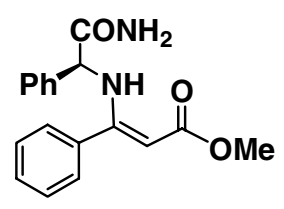
flash chromatography (40-60\% EtOAc/ hexane) to afford an oil, which was crystallized in $20 \% \mathrm{EtOAc} /$ hexane $(250 \mathrm{~mL})$ to afford after drying $19.7 \mathrm{~g}$ enamine $(56 \%$ yield). $[\alpha]_{\mathrm{D}}{ }^{25}=-68$ (c 0.49, DCM). mp $=142{ }^{\circ} \mathrm{C} .{ }^{1} \mathrm{H}-\mathrm{NMR}\left(\mathrm{DMSO}-\mathrm{d}_{6}, 400 \mathrm{MHz}\right): \delta 9.46$ (d, $J=$ $9 \mathrm{~Hz}, 1 \mathrm{H}), 7.65(\mathrm{~s}, 1 \mathrm{H}), 7.39(\mathrm{~m}, 1 \mathrm{H}), 7.33(\mathrm{~m}, 2 \mathrm{H}), 7.24(\mathrm{~m}, 4 \mathrm{H}), 7.11(\mathrm{~m}, 4 \mathrm{H}), 4.92(\mathrm{~d}$, $J=9 \mathrm{~Hz}, 1 \mathrm{H}), 4.51(\mathrm{~s}, 1 \mathrm{H}), 3.61(\mathrm{~s}, 3 \mathrm{H})$. nOe enhancement: $2.3 \%$ ortho phenyl hydrogens on main chain upon irradiation of the olefinic hydrogen. ${ }^{13} \mathrm{C}-\mathrm{NMR}$ (DMSO- $\mathrm{d}_{6}$, $100 \mathrm{MHz}): \delta$ 171.0, 169.0, 162.5, 140.0, 135.5, 129.2, 128.2, 128.2, 127.3, 127.2, 126.1, 86.4, 59.9, 49.8. Anal. Calcd for $\mathrm{C}_{19} \mathrm{H}_{20} \mathrm{~N}_{2} \mathrm{O}_{4}: \mathrm{C}, 67.05 ; \mathrm{H}, 5.92 ; \mathrm{N}, 8.23 ; \mathrm{O}, 18.80$. Found: C, 69.46; H, 5.99; N, 8.94; O, 16.66 .

8) (2S)-2-\{[(1Z)-3-oxo-1-phenyl-3-piperidin-1-ylprop-1-en-1yl]amino\}-2-phenylacetamide (2k). 3-Oxo-1-phenyl-3-piperidin-1ylpropan-1-one (10.1 g, $43.7 \mathrm{mmol})$ and $(S)$-PGA $(6.6 \mathrm{~g}, 44 \mathrm{mmol})$ in IPA $(40 \mathrm{~mL})$ and acetic acid $(1.9 \mathrm{~mL}, 33 \mathrm{mmol})$ were stirred 4 days at $40{ }^{\circ} \mathrm{C}$. The mixture was concentrated and purified by flash

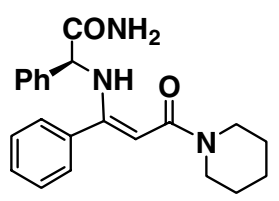
chromatography and crystallization (EtOAc/ hexane) to afford the enamine $(6.9 \mathrm{~g}, 43 \%)$. $[\alpha]_{\mathrm{D}}{ }^{25}=+86(\mathrm{c} 0.26, \mathrm{DCM}) . \mathrm{mp}=126^{\circ} \mathrm{C} .{ }^{1} \mathrm{H}-\mathrm{NMR}$ (DMSO-d $\left.{ }_{6}, 400 \mathrm{MHz}\right): \delta 10.17$ (d, $J$ 
$=9 \mathrm{~Hz}, 1 \mathrm{H}), 7.56(\mathrm{~s}, 1 \mathrm{H}), 7.07-7.37(\mathrm{~m}, 11 \mathrm{H}), 4.84(\mathrm{~s}, 1 \mathrm{H}), 4.80(\mathrm{~d}, J=9 \mathrm{~Hz}, 1 \mathrm{H}), 3.41$ (br, 4H), 1.56 (br, 2H), 1.33 (br, 4H). nOe enhancement: 3\% ortho phenyl hydrogens on main chain upon irradiation of the olefinic hydrogen. ${ }^{13} \mathrm{C}-\mathrm{NMR}$ (DMSO- $\mathrm{d}_{6}, 100 \mathrm{MHz}$ ): $\delta$ 171.5, 167.7, 160.0, 140.5, 137.0, 128.8, 128.2, 128.1, 127.5, 127.2, 126.4, 87.4, 60.4, 25.8, 24.3. HRMS (M+1) for $\mathrm{C}_{22} \mathrm{H}_{25} \mathrm{~N}_{3} \mathrm{O}_{2}$ calcd 364.2025 expt 364.2017

9) (2Z)-3-\{[(1S)-2-amino-2-oxo-1-phenylethyl]amino\}-3-

phenylacrylamide (2j). 3-Oxo-3-phenylpropanamide $(6.53 \mathrm{~g}, 40.0$ mmol) and (S)-PGA $(6.01 \mathrm{~g}, 40.0 \mathrm{mmol})$ in IPA $(35 \mathrm{~mL})$ and acetic acid $(1.2 \mathrm{~mL}, 20 \mathrm{mmol})$ were stirred 4 days at $40^{\circ} \mathrm{C}$. The mixture was concentrated and the residue was dissolved in EtOAc $(150 \mathrm{~mL})$. The

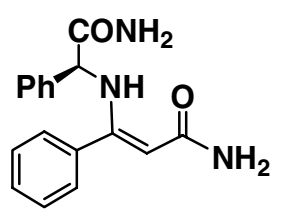
undissolved solids (PGA salt) were filtered off and the filtrate was concentrated. Purification by flash chromatography $(0-10 \% \mathrm{MeOH} / \mathrm{EtOAc})$ followed by crystallization afforded the enamine $\left(5.47 \mathrm{~g}, 46 \%\right.$ yield) as a white solid. $[\alpha]_{\mathrm{D}}^{25}=+18$ (c $\left.0.33, \mathrm{DCM}\right)$. $\mathrm{mp}=111-130{ }^{\circ} \mathrm{C} .{ }^{1} \mathrm{H}-\mathrm{NMR}\left(\mathrm{DMSO}_{6}, 400 \mathrm{MHz}\right): \delta 9.74(\mathrm{~d}, J=10 \mathrm{~Hz}, 1 \mathrm{H}), 7.58(\mathrm{~s}$, $1 \mathrm{H}), 7.33(\mathrm{~m}, 3 \mathrm{H}), 7.22(\mathrm{~m}, 3 \mathrm{H}), 7.16(\mathrm{~m}, 2 \mathrm{H}), 7.08(\mathrm{~m}, 3 \mathrm{H}), 6.9(\mathrm{br}, 1 \mathrm{H}), 6.3(\mathrm{br}, 1 \mathrm{H})$, $4.79(\mathrm{~d}, J=10 \mathrm{~Hz}, 1 \mathrm{H}), 4.60(\mathrm{~s}, 1 \mathrm{H})$. nOe enhancement: $1.9 \%$ ortho phenyl hydrogens on main chain upon irradiation of the olefinic hydrogen. ${ }^{13} \mathrm{C}-\mathrm{NMR}$ (DMSO- $\mathrm{d}_{6}, 100$ MHz): $\delta$ 172.0, 171.5, 159.2, 140.9, 137.1, 129.2, 128.6, 128.5, 127.8, 127.6, 126.8, 92.8, 60.8. HRMS (M+1) for $\mathrm{C}_{17} \mathrm{H}_{17} \mathrm{~N}_{3} \mathrm{O}_{2}$ calcd 296.1399 expt 296.1403

10) Methyl (2Z)-3-\{[(1S)-2-amino-2-oxo-1-phenylethyl]amino\}-3(4-methoxyphenyl)acrylate (2h)

Methyl 3-(4-methoxyphenyl)-3-oxopropanoate (10.41 g, $50.0 \mathrm{mmol})$ and $(S)$-PGA $(7.51 \mathrm{~g}, 50.0 \mathrm{mmol})$ in IPA $(40 \mathrm{~mL})$ and acetic acid Meo

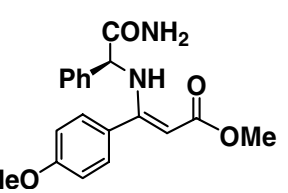
$(1.43 \mathrm{~mL}, 25 \mathrm{mmol})$ were stirred 5 days at $40{ }^{\circ} \mathrm{C}$. The mixture was concentrated and EtOAc $(50 \mathrm{~mL})$ was added. The undissolved solids (PGA salt) were filtered off and the filtrate was concentrated. The residue was purified by flash chromatography (30-100\% EtOAc/ hexane) to afford the enamine $(7.21 \mathrm{~g})$ as an amorphous solid, which was heated and stirred in MTBE $(150 \mathrm{~mL})$ to afford a slurry. The solids were filtered and dried to afford the enamine $(5.96 \mathrm{~g}, 35 \%) .[\alpha]_{\mathrm{D}}{ }^{25}=-31(\mathrm{c} 0.56, \mathrm{DCM}) . \mathrm{mp}=93{ }^{\circ} \mathrm{C}$ (broad). ${ }^{1} \mathrm{H}-$ NMR (DMSO-d $6,400 \mathrm{MHz}): \delta 9.41(\mathrm{~d}, J=8.9 \mathrm{~Hz}, 1 \mathrm{H}), 7.64(\mathrm{~s}, 1 \mathrm{H}), 7.26(\mathrm{~m}, 3 \mathrm{H}), 7.16$ $(\mathrm{m}, 3 \mathrm{H}), 7.05(\mathrm{~d}, J=8.5 \mathrm{~Hz}, 2 \mathrm{H}), 6.89(\mathrm{~d}, J=8.6 \mathrm{~Hz}, 2 \mathrm{H}), 4.95(\mathrm{~d}, J=8.9 \mathrm{~Hz}, 1 \mathrm{H}), 4.50$ (s, $1 \mathrm{H}), 3.75(\mathrm{~s}, 3 \mathrm{H}), 3.60(\mathrm{~s}, 3 \mathrm{H})$. nOe enhancement: $2.5 \%$ meta hydrogens to $\mathrm{CH}_{3} \mathrm{O}-$ upon irradiation of the olefinic hydrogen. ${ }^{13} \mathrm{C}-\mathrm{NMR}$ (DMSO-d $6,100 \mathrm{MHz}$ ): $\delta 171.2$, 169.1, 162.6, 160.0, 140.1, 128.8, 128.3, 127.9, 127.4, 126.2, 113.7, 86.3, 60.1, 55.2, 49.9. Anal. Calcd for $\mathrm{C}_{19} \mathrm{H}_{20} \mathrm{~N}_{2} \mathrm{O}_{4}$ : C, 67.05; H, 5.92; N, 8.23. Found: C, 66.74; H, 5.85; N, 7.89 .

\section{1) Methyl (2Z)-3-\{[(1S)-2-amino-2-oxo-1-phenylethyl]amino\}-3-[4- (trifluoromethyl)phenyl]acrylate (2i).}

Methyl 3-oxo-3-[4-(trifluoromethyl)phenyl]propanoate (5.18 g, 20.0 $\mathrm{mmol})$ and $(S)$-PGA $(3.00 \mathrm{~g}, 20.0 \mathrm{mmol})$ in IPA $(25 \mathrm{~mL})$ and acetic acid $(1.2 \mathrm{~mL}, 20 \mathrm{mmol})$ were stirred 2 days at $40{ }^{\circ} \mathrm{C}$. The mixture was cooled to RT, n-heptane $(10 \mathrm{~mL})$ was added to precipitate the

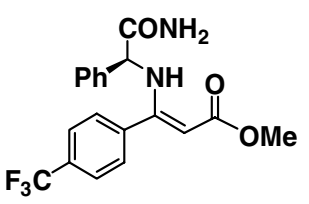
unreacted PGA and filtered. The filtrate was concentrated and the residue was purified 
by flash chromatography (50-70\% EtOAc/ hexane) to afford the enamine as an amorphous solid $(6.2 \mathrm{~g}, 82 \%)$ which contained a small amount of the E-enamine isomer. The solids were crystallized from MTBE to afford the pure Z-enamine $(4.18 \mathrm{~g}, 55 \%)$ as a white solid. $[\alpha]_{\mathrm{D}}{ }^{25}=-79$ (c 0.57, DCM). $\mathrm{mp}=91{ }^{\circ} \mathrm{C}$ (broad). ${ }^{1} \mathrm{H}-\mathrm{NMR}$ (DMSO-d 6,400 MHz): $\delta 9.43$ (d, $J=8.6 \mathrm{~Hz}, 1 \mathrm{H}), 7.70(\mathrm{~d}, J=8 \mathrm{~Hz}, 2 \mathrm{H}), 7.60(\mathrm{~s}, 1 \mathrm{H}), 7.30(\mathrm{~d}, J=8 \mathrm{~Hz}$, $2 \mathrm{H}), 7.24(\sim \mathrm{t}, 4 \mathrm{H}), 7.10(\mathrm{~d}, J=6.5 \mathrm{~Hz}, 2 \mathrm{H}), 4.86(\mathrm{~d}, J=8.6 \mathrm{~Hz}, 1 \mathrm{H}), 4.57(\mathrm{~s}, 1 \mathrm{H}), 3.62$ $(\mathrm{s}, 3 \mathrm{H})$. nOe enhancement: $2.1 \%$ meta hydrogens to $\mathrm{CF}_{3}$ upon irradiation of the olefinic hydrogen. ${ }^{13} \mathrm{C}-\mathrm{NMR}$ (DMSO-d $6,100 \mathrm{MHz}$ ): $\delta 170.8,168.9,160.9,139.8,139.6,128.4$, 128.3, 127.6, 126.2, 125.2, 87.3, 59.9, 50.1. Anal. Calcd for $\mathrm{C}_{19} \mathrm{H}_{17} \mathrm{~F}_{3} \mathrm{~N}_{2} \mathrm{O}_{3}$ : C, 60.32; $\mathrm{H}$, 4.53; N, 7.40; F, 15.06. Found: C, 60.23; H, 4.36; N, 7.37; F, 14.96.

\section{Hydrogenated PGA-Amines:}

General Procedure: A pressure reaction vessel is charged with the $\mathrm{PGA}$-enamine, $\mathrm{PtO}_{2}$ and THF and the resulting slurry is cooled to $0{ }^{\circ} \mathrm{C}$. The vessel is pressure purged with nitrogen ( 3 x $40 \mathrm{psig})$ and hydrogen ( 2 x $40 \mathrm{psig}$ ) and then pressurized with hydrogen (90 psig). The reaction mixture is agitated for 30 minutes and then allowed to warm to room temperature over $15 \mathrm{~min}$. After stirring for the prescribed amount of time (see Tables 1 and 3 in paper), the vessel is carefully vented to atmospheric pressure and the resulting slurry is filtered through Solka floc. The filter cake is rinsed with THF (3x) and the filtrates are combined and concentration. The residue was purified by flash chromatograph (EtOAc/ hexane) and was crystallized (EtOAc/ hexane) when possible. CAUTION: The reduced platinum catalyst is pyrophoric, should be kept wet with solvent, and exposure to air should be minimized.

1) Methyl (3R)-3-\{[(1S)-2-amino-2-oxo-1phenylethyl]amino\}butanoate (3a). Flash chromatography $(90 \%$ EtOAc/ hexane) afforded the ester $(0.17 \mathrm{~g}, 66 \%$ yield $) .{ }^{1} \mathrm{H}-\mathrm{NMR}$ (DMSO-d $\left.\mathrm{d}_{6}, 400 \mathrm{MHz}\right): \delta 7.57$ (bs, $\left.1 \mathrm{H}\right), 7.45(\mathrm{~m}, 2 \mathrm{H}), 7.39(\mathrm{~m}, 2 \mathrm{H})$,

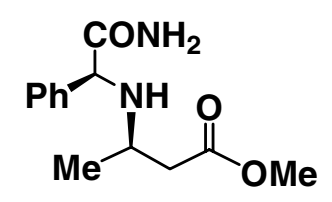
$7.33(\mathrm{~m}, 1 \mathrm{H}), 7.20$ (bs, $1 \mathrm{H}), 4.31(\mathrm{bd}, J=4 \mathrm{~Hz}, 1 \mathrm{H}), 3.67$ (s, 3H), 2.99 (m, 1H), 2.59 (dd, $J=15,7 \mathrm{~Hz}, 2 \mathrm{H}), 2.38(\mathrm{dd}, J=15,7 \mathrm{~Hz}, 2 \mathrm{H}), 1.11(\mathrm{~d}, J=6 \mathrm{~Hz}, 3 \mathrm{H}) .{ }^{13} \mathrm{C}-\mathrm{NMR}$ (DMSO$\left.\mathrm{d}_{6}, 100 \mathrm{MHz}\right): \delta 174.1,172.2,140.6,128.1,127.3,127.2,63.0,51.247 .9$ 41.3, 19.8. HRMS (M+1) for $\mathrm{C}_{13} \mathrm{H}_{18} \mathrm{~N}_{2} \mathrm{O}_{3}$ calcd 251.1396 expt 251.1396

2) Methyl (3S)-3-\{[(1S)-2-amino-2-oxo-1-phenylethyl]amino\}-4methylpentanoate (3b). Flash chromatography (70-85\% EtOAc/ hexane) afforded pure amine $\left(0.27 \mathrm{~g}, 82 \%\right.$ yield). ${ }^{1} \mathrm{H}-\mathrm{NMR}\left(\right.$ DMSO- $_{6}$, $400 \mathrm{MHz}): \delta 7.42$ (bs, 1H), $7.37(\mathrm{~m}, 2 \mathrm{H}), 7.31(\mathrm{~m}, 2 \mathrm{H}), 7.24(\mathrm{~m}, 1 \mathrm{H})$,

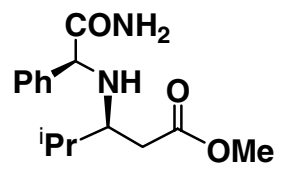
$7.12(\mathrm{bs}, 1 \mathrm{H}), 4.20(\mathrm{~d}, J=6 \mathrm{~Hz}, 1 \mathrm{H}), 3.59(\mathrm{~s}, 3 \mathrm{H}), 2.68(\mathrm{~m}, 1 \mathrm{H}), 2.33(\mathrm{~m}, 2 \mathrm{H}), 1.77(\mathrm{~m}$, $1 \mathrm{H}), 0.83(\mathrm{~d}, J=7 \mathrm{~Hz}, 3 \mathrm{H}), 0.76(\mathrm{~d}, J=7 \mathrm{~Hz}, 3 \mathrm{H}) .{ }^{13} \mathrm{C}-\mathrm{NMR}$ (DMSO-d $\left.6,100 \mathrm{MHz}\right)$ : $\delta 174.1,172.8,140.7,128.0,127.4,127.1,63.2,57.4,51.3,29.7,18.3,17.4$. HRMS $(\mathrm{M}+1)$ for $\mathrm{C}_{15} \mathrm{H}_{21} \mathrm{~N}_{2} \mathrm{O}_{3}$ calcd 279.1709 found 279.1705

3) Methyl (3R)-3-\{[(1S)-2-amino-2-oxo-1-phenylethyl]amino\}-4phenylbutanoate (3c). Flash chromatography $(80-100 \%$ EtOAc/

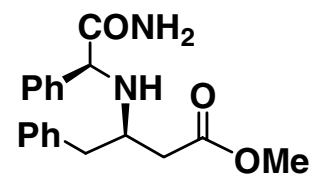


hexane) afforded the amine as a resin $(0.25 \mathrm{~g}, 88 \%$ yield $)$. This was crystallized from EtOAc/ hexane. ${ }^{1} \mathrm{H}-\mathrm{NMR}$ (DMSO-d $\left.{ }_{6}, 400 \mathrm{MHz}\right): \delta 7.45(\mathrm{~s}, 1 \mathrm{H}), 7.24(\mathrm{~m}, 8 \mathrm{H}), 7.11(\mathrm{~m}$, $3 \mathrm{H}), 4.31(\mathrm{~d}, J=6.5 \mathrm{~Hz}, 1 \mathrm{H}), 3.55(\mathrm{~s}, 3 \mathrm{H}), 2.97(\mathrm{~m}, 1 \mathrm{H}), 2.80(\mathrm{dd}, \mathrm{J}=6.0,13.3 \mathrm{~Hz}, 1 \mathrm{H})$, $2.58(\mathrm{dd}, J=7.013 .3 \mathrm{~Hz}, 1 \mathrm{H}), 2.37-2.46(\mathrm{~m}, 2 \mathrm{H}), 2.29(\mathrm{dd}, J=5.8,15.2 \mathrm{~Hz}, 1 \mathrm{H}) .{ }^{13} \mathrm{C}-$ NMR (DMSO-d $6,100 \mathrm{MHz}): \delta 173.8,172.1,140.2,138.7,129.2,128.2,128.0,127.2$, 127.2, 126.1, 62.8, 54.0, 51.4, 38.5. HRMS (M+1) for $\mathrm{C}_{19} \mathrm{H}_{22} \mathrm{~N}_{2} \mathrm{O}_{3}$ calcd 327.1709 expt. 327.1701

4) (2S)-2-\{[(1R)-1-benzyl-3-oxo-3-piperidin-1-ylpropyl]amino\}-2phenylacetamide (3f). Flash chromatography (5\% MeOH/ EtOAc) afforded the amine as an oil which was crystallized from 1:1 EtOAc/ hexane to afford the product as a white solid $\left(1.02 \mathrm{~g}, 88 \%\right.$ yield). ${ }^{1} \mathrm{H}-$

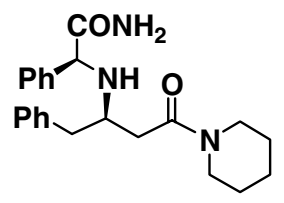
NMR (DMSO-d $6,400 \mathrm{MHz}): \delta 7.65(\mathrm{~s}, 1 \mathrm{H}), 7.1-7.3(\mathrm{~m}, 11 \mathrm{H}), 4.33(\mathrm{~d}, J=4.6 \mathrm{~Hz}, 1 \mathrm{H})$, $3.39(\mathrm{~m}, 2 \mathrm{H}), 3.20(\mathrm{~m}, 2 \mathrm{H}), 2.98(\mathrm{~m}, 1 \mathrm{H}), 2.81(\mathrm{dd}, J=5.7,13.2 \mathrm{~Hz}, 1 \mathrm{H}), 2.59(\mathrm{dd}, J=$ $6.9,13.2 \mathrm{~Hz}, 1 \mathrm{H}), 2.3-2.5(\mathrm{~m}, 2 \mathrm{H}), 2.22(\mathrm{dd}, J=5.5,15.2 \mathrm{~Hz}, 1 \mathrm{H}), 1.52(\mathrm{~m}, 2 \mathrm{H}), 1.36$ $(\mathrm{m}, 4 \mathrm{H}) .{ }^{13} \mathrm{C}-\mathrm{NMR}$ (DMSO-d $\left.6,100 \mathrm{MHz}\right): \delta 174.1,169.1,140.5,139.2,129.3,128.2$, 128.0, 127.3, 127.1, 126.0, 62.9, 54.2, 45.9, 41.8, 37.0, 26.0, 25.2, 23.9. HRMS (M+1) for $\mathrm{C}_{23} \mathrm{H}_{29} \mathrm{~N}_{3} \mathrm{O}_{2}$ calcd 380.2346 found 380.2338

5) (3R)-3-\{[(1S)-2-amino-2-oxo-1-phenylethyl]amino\}-4-

phenylbutanamide (3e). Stirring the residue in 1:1 EtOAc/ hexane followed by filtration and drying afforded the amine as a white solid (0.20 g, 98\% yield). ${ }^{1} \mathrm{H}-\mathrm{NMR}$ (DMSO-d $\left.6,400 \mathrm{MHz}\right): \delta 7.64(\mathrm{~s}, 1 \mathrm{H})$, $7.46(\mathrm{~s}, 1 \mathrm{H}), 7.25(\mathrm{~m}, 8 \mathrm{H}), 7.11(\mathrm{~m}, 3 \mathrm{H}), 6.83(\mathrm{~s}, 1 \mathrm{H}), 4.36(\mathrm{~s}, 1 \mathrm{H})$,<smiles>NC(=O)CC(NC(Cc1ccccc1)C(N)=O)c1ccccc1</smiles>
2.97 (br, 1H), 2.80 (dd, $J=5.5,13.2 \mathrm{~Hz}, 1 \mathrm{H}), 2.57$ (dd, $J=7.0,13.2 \mathrm{~Hz}, 1 \mathrm{H}), 2.28$ (br, $1 \mathrm{H}), 2.10(\mathrm{~m}, 2 \mathrm{H}) .{ }^{13} \mathrm{C}-\mathrm{NMR}$ (DMSO-d $6,100 \mathrm{MHz}$ ): $\delta$ 174.1, 173.2, 140.5, 139.0, 129.3, 128.2, 128.0, 127.3, 127.2, 126.0, 62.8, 53.9, 39.4. HRMS (M+1) for $\mathrm{C}_{18} \mathrm{H}_{21} \mathrm{~N}_{3} \mathrm{O}_{2}$ calcd 312.1712 found 312.1717

6) Methyl (1S,2R)-2-\{[(1S)-2-amino-2-oxo-1phenylethyl]amino\}cyclohexanecarboxylate (3d).

Flash chromatography (75\% EtOAc/ hexane) afforded the pure amine (1.79 g, 94\% yield). ${ }^{1} \mathrm{H}-\mathrm{NMR}$ (DMSO-d ${ }_{6}, 400 \mathrm{MHz}$ ): $\delta 7.42$ (bs, $\left.1 \mathrm{H}\right)$, $7.36(\mathrm{~m}, 2 \mathrm{H}), 7.31(\mathrm{~m}, 2 \mathrm{H}), 7.25(\mathrm{~m}, 1 \mathrm{H}), 4.18(\mathrm{~d}, 1 \mathrm{H}), 3.62(\mathrm{~s}, 3 \mathrm{H})$,

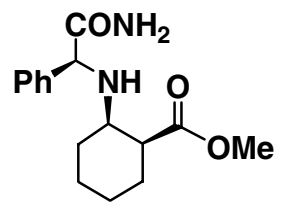
$2.89(\mathrm{bm}, 1 \mathrm{H}), 2.63(\mathrm{~m}, 1 \mathrm{H}), 2.28(\mathrm{t}, J=6 \mathrm{~Hz}, 1 \mathrm{H}), 1.78(\mathrm{q}, J=10 \mathrm{~Hz}, 1 \mathrm{H}), 1.70(\mathrm{~m}$, $1 \mathrm{H}), 1.50(\mathrm{bm}, 4 \mathrm{H}), 1.25(\mathrm{bm}, 2 \mathrm{H}) .{ }^{13} \mathrm{C}-\mathrm{NMR}$ (DMSO-d $\left.6,100 \mathrm{MHz}\right): \delta 174.1,174.0$, $140.9,128.1,127.2,62.9,59.7,52.8,51.1,45.4,28.5,23.8,23.4,20.7,14.1$. HRMS $(\mathrm{M}+1)$ for $\mathrm{C}_{16} \mathrm{H}_{22} \mathrm{~N}_{2} \mathrm{O}_{3}$ calcd 291.1709 expt 291.1707

7) Methyl (3S)-3-\{[(1S)-2-amino-2-oxo-1-phenylethyl $]$ amino\}-3phenylpropanoate $\mathbf{( 3 g})$. Flash chromatography $(75 \% \mathrm{EtOAc/}$ hexane) afforded the pure amine as a resin. ${ }^{1} \mathrm{H}-\mathrm{NMR}$ (DMSO- $\mathrm{d}_{6}, 400$ MHz): $\delta 7.59$ (d, $J=2.4 \mathrm{~Hz}, 1 \mathrm{H}), 7.2-7.3(\mathrm{~m}, 11 \mathrm{H}), 3.98(\mathrm{q}, J=7.7$ $\mathrm{Hz}, 1 \mathrm{H}), 3.72(\mathrm{~d}, J=5.3 \mathrm{~Hz}, 1 \mathrm{H}), 3.56(\mathrm{~s}, 3 \mathrm{H}), 3.14(\mathrm{~m}, 1 \mathrm{H}), 2.86$

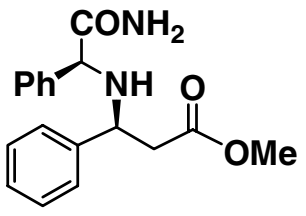
(dd, $J=8.1,15.4 \mathrm{~Hz}, 1 \mathrm{H}), 2.58(\mathrm{dd}, J=6.4,15.4 \mathrm{~Hz}, 1 \mathrm{H}) .{ }^{13} \mathrm{C}-\mathrm{NMR}\left(\right.$ DMSO-d $_{6}, 100$ 
MHz): $\delta$ 173.9, 171.6, 142.4, 140.1, 128.5, 128.2, 127.4, 127.4, 127.3, 127.2, 63.5, 57.6, 51.4, 42.3. HRMS (M+1) for $\mathrm{C}_{18} \mathrm{H}_{20} \mathrm{~N}_{2} \mathrm{O}_{3}$ calcd 313.1552 expt. 313.1556

8) (2S)-2-[(3-oxo-1-phenyl-3-piperidin-1-ylpropyl)amino]-2-

phenylacetamide (3k). Flash chromatography (EtOAc/ hexane) afforded the amine as a white solid foam $\left(0.41 \mathrm{~g}, 92 \%\right.$ yield). ${ }^{1} \mathrm{H}-$ NMR (DMSO-d 6 , $400 \mathrm{MHz}): \delta 7.99(\mathrm{~s}, 1 \mathrm{H}), 7.36-7.19(\mathrm{~m}, 11 \mathrm{H})$, $4.03(\mathrm{~m}, 1 \mathrm{H}), 3.70(\mathrm{~d}, J=5 \mathrm{~Hz}, 1 \mathrm{H}), 3.46(\mathrm{~m}, 1 \mathrm{H}), 3.35(\mathrm{~m}, 1 \mathrm{H}), 3.30$

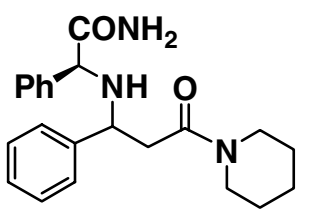
(m, 3H), 3.01 (bt, $1 \mathrm{H}), 2.81(\mathrm{dd}, J=8.6,15 \mathrm{~Hz}, 1 \mathrm{H}), 2.52(\mathrm{dd}, 4.9,15 \mathrm{~Hz}, 1 \mathrm{H}), 1.52(\mathrm{~m}$, 2H), $1.39(4 \mathrm{H}) .{ }^{13} \mathrm{C}-\mathrm{NMR}$ (DMSO-d $6,100 \mathrm{MHz}$ ): $\delta 174.1,168.6,143.2,140.5,128.3$, 128.1, 127.2, 127.2, 127.0, 63.6, 57.8, 46.0, 42.0, 40.7, 25.8, 25.2, 24.0. HRMS (M+1) for $\mathrm{C}_{22} \mathrm{H}_{27} \mathrm{~N}_{3} \mathrm{O}_{2}$ calcd 366.2181 expt. 366.2179

9) 3-\{[(1S)-2-amino-2-oxo-1-phenylethyl]amino\}-3-

phenylpropanamide (3j). Suspension of the residue in EtOAc/ hexane and filtration afforded the product as a white solid $(0.25 \mathrm{~g}, 80 \%$ yield $)$. ${ }^{1} \mathrm{H}-\mathrm{NMR}$ (DMSO-d $\left.6,400 \mathrm{MHz}\right): \delta 7.74(\mathrm{~s}, 1 \mathrm{H}), 7.42(\mathrm{~s}, 1 \mathrm{H}), 7.32(\mathrm{~m}$,

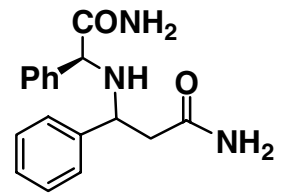
$4 \mathrm{H}), 7.24(\mathrm{~m}, 6 \mathrm{H}), 7.16(\mathrm{~s}, 1 \mathrm{H}), 6.83(\mathrm{~s}, 1 \mathrm{H}), 3.97(\mathrm{bq}, 1 \mathrm{H}), 3.74(\mathrm{~d}, \mathrm{~J}=5 \mathrm{~Hz}, 1 \mathrm{H}), 3.05$ (bt, $1 \mathrm{H}), 2.52(\mathrm{dd}, J=9.1,15 \mathrm{~Hz}, 1 \mathrm{H}), 2.30(\mathrm{dd}, J=5.1,15 \mathrm{~Hz}, 1 \mathrm{H}) .{ }^{13} \mathrm{C}-\mathrm{NMR}$ (DMSO$\left.\mathrm{d}_{6}, 100 \mathrm{MHz}\right): \delta 174.0,172.5,143.2,140.4,128.3,128.1,127.2,127.1,127.1,63.3,57.5$, 43.7. HRMS (M+1) for $\mathrm{C}_{17} \mathrm{H}_{19} \mathrm{~N}_{3} \mathrm{O}_{2}$ calcd 298.1555 expt. 298.1561

10) methyl 3-\{[(1S)-2-amino-2-oxo-1-phenylethyl]amino\}-3-(4methoxyphenyl)propanoate (3h). Crystallization from EtOAc/ hexane afforded the amine as a white solid $(0.40 \mathrm{~g}, 46 \%$ yield $)$. ${ }^{1} \mathrm{H}-\mathrm{NMR}$ (DMSO-d $\left.6,400 \mathrm{MHz}\right): \delta 7.55(\mathrm{~s}, 1 \mathrm{H}), 7.23(\mathrm{~m}, 8 \mathrm{H})$, 6.89 (d, $J=8.6 \mathrm{~Hz}, 2 \mathrm{H}), 3.92$ (br-q, $1 \mathrm{H}), 3.74(\mathrm{~s}, 3 \mathrm{H}), 3.72(1 \mathrm{H})$,

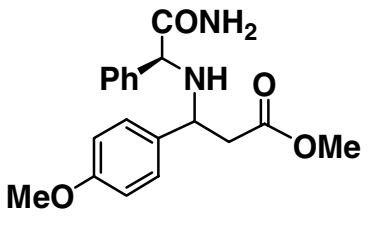
3.55 (s, 3H), 3.06 (br-t, 1H), 2.84 (dd, $J=8,15 \mathrm{~Hz}, 1 \mathrm{H}), 2.54$ (dd, $J=6.5,15 \mathrm{~Hz}, 1 \mathrm{H})$. ${ }^{13} \mathrm{C}-\mathrm{NMR}$ (DMSO-d $6,100 \mathrm{MHz}$ ): $\delta 173.8,171.5,158.4,140.1,134.1,128.2,128.1$, 127.2, 127.1, 113.7, 63.3, 56.8, 55.0, 51.2, 42.4. HRMS (M+1) for $\mathrm{C}_{19} \mathrm{H}_{22} \mathrm{~N}_{2} \mathrm{O}_{4}$ calcd 343.1658 expt. 343.1663

11) Methyl 3-\{[(1S)-2-amino-2-oxo-1-phenylethyl]amino\}-3-[4(trifluoromethyl)phenyl]propanoate (3i). Flash chromatography (80\% EtOAc/ hexane) afforded the amine as a resin. ${ }^{1} \mathrm{H}-\mathrm{NMR}$ $\left(\mathrm{CD}_{3} \mathrm{OD}, 400 \mathrm{MHz}\right): \delta 7.66(\mathrm{~d}, J=8 \mathrm{~Hz}, 2 \mathrm{H}), 7.54(\mathrm{~d}, J=8 \mathrm{~Hz}$, $2 \mathrm{H}), 7.27(\mathrm{~m}, 5 \mathrm{H}), 4.25(\mathrm{~m}, 1 \mathrm{H}), 3.88(\mathrm{~s}, 1 \mathrm{H}), 3.68(\mathrm{~s}, 3 \mathrm{H}), 2.89$ $(\mathrm{dd}, J=9.0,16.0 \mathrm{~Hz}, 1 \mathrm{H}), 2.70(\mathrm{dd}, J=5.6,16.0 \mathrm{~Hz}, 1 \mathrm{H}) \cdot{ }^{13} \mathrm{C}-\mathrm{NMR}\left(\mathrm{CD}_{3} \mathrm{OD}, 100\right.$ MHz): $\delta$ 178.0, 173.6, 148.0, 140.7, 129.8, 129.3, 129.2, 128.7, 126.8, 126.8, 65.6, 59.1, 52.4, 43.0. HRMS $(\mathrm{M}+1)$ for $\mathrm{C}_{19} \mathrm{H}_{19} \mathrm{~F}_{3} \mathrm{~N}_{2} \mathrm{O}_{3}$ calcd 381.1426 expt. 381.1433

\section{Deprotected Amines:}

General Procedure: A pressure reaction vessel is charged with PGA-amine, acetic acid (2.5 molar equiv), water, THF, and $30 \% \mathrm{Pd}(\mathrm{OH})_{2}(20 \mathrm{wt} \%$ based on PGA-amine) and 
warmed to $50{ }^{\circ} \mathrm{C}$. The vessel is pressure purged with nitrogen $(3 \mathrm{x} 40 \mathrm{psig}$ ) and pressurized with hydrogen (40 psig) and the reaction solution is stirred for 12 hours. After cooling to room temperature, the vessel is vented and the solution is filtered through Solka floc. The filter cake is then washed with THF. CAUTION: The reduced palladium catalyst is pyrophoric, should be kept wet with solvent, and exposure to air should be minimized. The filtrates are combined and the solvent is removed under reduced pressure to yield a mixture of the desired $\beta$-amino acid derivative as the acetate salt and 2-phenylacetamide byproduct. The assay yield of the amine salt was determined by ${ }^{1} \mathrm{H}$-NMR using added dichloromethane as an internal reference. The stereochemical assignment was made by measuring the optical rotation of the crude product as its $\mathrm{HCl}$ salt and comparing its sign with what is reported in the literature or of an authentic reference sample. The $\mathrm{HCl}$ salt was prepared by addition of $\mathrm{HCl} /$ ether and evaporation to dryness.

1) Methyl (3R)-3-aminobutanoate acetate Assay yield was 99\%. ${ }^{1} \mathrm{H}-\mathrm{NMR}\left(\mathrm{CD}_{3} \mathrm{OD}, 400 \mathrm{MHz}\right): \delta 3.73$ (s, 3H), $3.65(\mathrm{~m}, 1 \mathrm{H}), 2.70(\mathrm{~m}, 2 \mathrm{H}), 1.95(\mathrm{~s}, 3 \mathrm{H}), 1.34(\mathrm{~d}, J=$

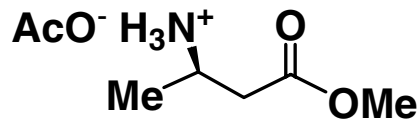
$6.6 \mathrm{~Hz}, 3 \mathrm{H}) .{ }^{13} \mathrm{C}-\mathrm{NMR}\left(\mathrm{CD}_{3} \mathrm{OD}, 100 \mathrm{MHz}\right): \delta 178.4,172.5,52.8,45.6,39.1,23.0,18.9$. HRMS $(\mathrm{M}+1)$ for $\mathrm{C}_{5} \mathrm{H}_{11} \mathrm{NO}_{2}$ calcd 118.0868 expt. 118.0864. Observed (HCl salt): $[\alpha]_{\mathrm{D}}{ }^{27}=$ negative (water) (Thus, stereochemistry is $R$ as shown). Literature for $(R)$ enantiomer ( $\mathrm{HCl}$ salt): $[\alpha]_{\mathrm{D}}{ }^{28}=-37.0$ (c 0.73, water). J. Org. Chem. 1992, 57, 2396.

2) Methyl (3S)-3-amino-4-methylpentanoate acetate Assay yield was $85 \%$. ${ }^{1} \mathrm{H}-\mathrm{NMR}\left(\mathrm{CD}_{3} \mathrm{OD}, 400 \mathrm{MHz}\right): \delta 3.74$ $(\mathrm{s}, 3 \mathrm{H}), 3.38(\mathrm{~m}, 1 \mathrm{H}), 2.76(\mathrm{dd}, J=4.0,17.3 \mathrm{~Hz}, 1 \mathrm{H}), 2.59$

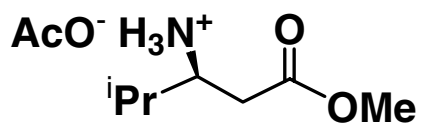
$(\mathrm{dd}, J=8.7,17.3 \mathrm{~Hz}, 1 \mathrm{H}), 1.96(\mathrm{~m}, 1 \mathrm{H}), 1.93(\mathrm{~s}, 3 \mathrm{H}), 1.01(\sim \mathrm{t}, 6 \mathrm{H}) .{ }^{13} \mathrm{C}-\mathrm{NMR}\left(\mathrm{CD}_{3} \mathrm{OD}\right.$, $100 \mathrm{MHz}): \delta 179.3,173.4,55.2,53.1,35.5,32.3,23.7,19.0,18.5$. HRMS $(\mathrm{M}+1)$ for $\mathrm{C}_{7} \mathrm{H}_{15} \mathrm{NO}_{2}$ calcd 146.1181 expt. 146.1178. Observed $(\mathrm{HCl}$ salt $):[\alpha]_{D}{ }^{25}=$ negative $(\mathrm{MeOH})$ (Thus, stereochemistry is $S$ as drawn). Literature for the $(R)$-enantiomer $(\mathrm{HCl}$ salt): $[\alpha]_{\mathrm{D}}^{25}=+28.2(\mathrm{c} 0.48, \mathrm{MeOH})$. Tetrahedron 1995, 51, 12337.

3) Methyl (3R)-3-amino-4-phenylbutanoate acetate Assay yield was $72 \% .{ }^{1} \mathrm{H}-\mathrm{NMR}\left(\mathrm{CD}_{3} \mathrm{OD}, 400 \mathrm{MHz}\right): \delta 7.3(\mathrm{~m}$, $5 \mathrm{H}), 3.71(\mathrm{~m}, 1 \mathrm{H}), 3.69(\mathrm{~s}, 3 \mathrm{H}), 2.64(\mathrm{dd}, J=4.8,17.0 \mathrm{~Hz}, 1 \mathrm{H})$,

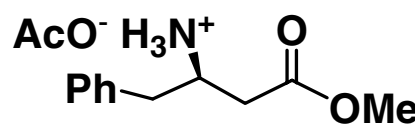
$2.54(\mathrm{dd}, J=7.8,17.0 \mathrm{~Hz}, 1 \mathrm{H}), 1.94(\mathrm{~s}, 3 \mathrm{H}) .{ }^{13} \mathrm{C}-\mathrm{NMR}\left(\mathrm{CD}_{3} \mathrm{OD}, 100 \mathrm{MHz}\right): \delta 172.9$, 137.5, 130.6, 130.2, 128.6, 52.7, 51.0, 40.9, 37.9, 23.1. HRMS (M+1) for $\mathrm{C}_{11} \mathrm{H}_{15} \mathrm{NO}_{2}$ calcd 194.1181 expt. 194.1184. Observed ( $\mathrm{HCl}$ salt): $[\alpha]_{\mathrm{D}}{ }^{25}=$ negative $(\mathrm{MeOH})$ (Thus, stereochemistry is $R$ as drawn). Literature for the $(R)$-enantiomer $\left(\mathrm{HCl}\right.$ salt): $[\alpha]_{\mathrm{D}}=-9.2$ (c 1.5, MeOH). Biosci. Biotech. Biochem., 1996, 60, 916.

4) [(1R)-1-benzyl-3-oxo-3-piperidin-1-ylpropyl]amine acetate Assay yield was 92\%. ${ }^{1} \mathrm{H}-\mathrm{NMR}\left(\mathrm{CD}_{3} \mathrm{OD}, 400 \mathrm{MHz}\right): \delta 7.3(\mathrm{~m}$, $5 \mathrm{H}), 3.78(\mathrm{~m}, 1 \mathrm{H}), 3.52(\mathrm{~m}, 2 \mathrm{H}), 3.32(\mathrm{~m}, 2 \mathrm{H}), 3.08(\mathrm{dd}, J=6.3$, $13.7 \mathrm{~Hz}, 1 \mathrm{H}), 2.96$ (dd, $J=8.5,13.7 \mathrm{~Hz}, 1 \mathrm{H}), 2.64(\mathrm{~m}, 2 \mathrm{H}), 1.96$

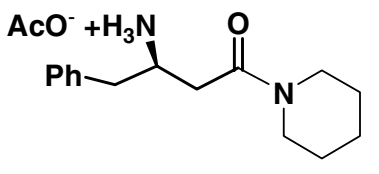


$(\mathrm{s}, 3 \mathrm{H}), 1.63(\mathrm{~m}, 2 \mathrm{H}), 1.51(\mathrm{~m}, 4 \mathrm{H}) .{ }^{13} \mathrm{C}-\mathrm{NMR}\left(\mathrm{CD}_{3} \mathrm{OD}, 100 \mathrm{MHz}\right): \delta 177.9,169.8$, 137.3, 130.6, 130.2, 128.6, 51.5, 49.2, 47.6, 44.0, 39.6, 34.6, 27.4, 26.7, 25.4, 22.8. HRMS (M+1) for $\mathrm{C}_{15} \mathrm{H}_{22} \mathrm{~N}_{2} \mathrm{O}$ calcd 247.1810 expt. 247.1802. Observed ( $\mathrm{HCl}$ salt): $[\alpha]_{\mathrm{D}}{ }^{20}=$ negative $(\mathrm{MeOH})$ (Thus, stereochemistry is $R$ as shown). Authentic sample of $(S)$-enantiomer ( $\mathrm{HCl}$ salt), prepared from Boc-L- $\beta$-homophenylalanine via EDC coupling with piperidine, followed by $\mathrm{HCl}$ deprotection: $[\alpha]_{\mathrm{D}}{ }^{20}=+37(\mathrm{c} 1.4, \mathrm{MeOH})$.

5) (3R)-3-amino-4-phenylbutanamide acetate

Assay yield was $93 \% .{ }^{1} \mathrm{H}-\mathrm{NMR}\left(\mathrm{CD}_{3} \mathrm{OD}, 400 \mathrm{MHz}\right): \delta 7.3(\mathrm{~m}$, $5 \mathrm{H}), 3.75(\mathrm{~m}, 1 \mathrm{H}), 3.07(\mathrm{dd}, J=6.1,13.7 \mathrm{~Hz}, 1 \mathrm{H}), 2.90(\mathrm{dd}, J=$

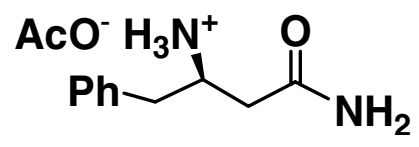
8.6, $13.7 \mathrm{~Hz}, 1 \mathrm{H}), 2.55(\mathrm{~m}, 2 \mathrm{H}), 1.96(\mathrm{~s}, 3 \mathrm{H}) .{ }^{13} \mathrm{C}-\mathrm{NMR}\left(\mathrm{CD}_{3} \mathrm{OD}, 100 \mathrm{MHz}\right): \delta 178.4$, 175.2, 136.9, 130.6, 130.2, 128.6, 51.4, 39.7, 36.4, 23.0. HRMS (M+1) for $\mathrm{C}_{10} \mathrm{H}_{14} \mathrm{~N}_{2} \mathrm{O}$ calcd 179.1184 expt. 179.1176. Observed $\left(\mathrm{HCl}\right.$ salt): $[\alpha]_{\mathrm{D}}{ }^{20}=$ negative $(\mathrm{MeOH})($ Thus, stereochemistry is $R$ as shown). Authentic sample of $(S)$-enantiomer ( $\mathrm{HCl}$ salt), prepared from Boc-L- $\beta$-homophenylalanine via EDC coupling with ammonia, followed by $\mathrm{HCl}$ deprotection: $[\alpha]_{\mathrm{D}}{ }^{20}=+11(\mathrm{c} 1.0, \mathrm{MeOH})$.

6) Methyl (1S,2R)-2-aminocyclohexanecarboxylate acetate Assay yield was $60 \% .{ }^{1} \mathrm{H}-\mathrm{NMR}\left(\mathrm{CD}_{3} \mathrm{OD}, 400 \mathrm{MHz}\right): \delta 3.73(\mathrm{~s}$, $3 \mathrm{H}), 3.40(\mathrm{~m}, 1 \mathrm{H}), 2.96(\sim \mathrm{q}, 1 \mathrm{H}), 2.05(\mathrm{~m}, 1 \mathrm{H}), 1.89(\sim \mathrm{s}, 3 \mathrm{H})$, $1.82(\mathrm{~m}, 2 \mathrm{H}), 1.69(\mathrm{~m}, 2 \mathrm{H}), 1.3-1.6(\mathrm{~m}, 3 \mathrm{H}) .{ }^{13} \mathrm{C}-\mathrm{NMR}\left(\mathrm{CD}_{3} \mathrm{OD}\right.$,

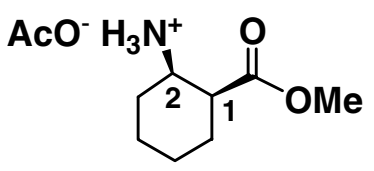
$100 \mathrm{MHz}): \delta 179.2,174.8,52.7,51.1,43.8,28.9,27.3,23.8,23.6,23.5$; HRMS (M+1) for $\mathrm{C}_{8} \mathrm{H}_{15} \mathrm{NO}_{2}$ calcd 158.1181 expt. 158.1180 . Observed $\left(\mathrm{HCl}\right.$ salt): $[\alpha]_{\mathrm{D}}{ }^{25}=$ positive ( $\mathrm{MeOH}$ ) (Thus, stereochemistry is $1 S, 2 R$ as drawn). Literature for $(1 R, 2 S)$-enantiomer (HCl salt): $[\alpha]_{\mathrm{D}}=-0.9(\mathrm{c} 0.51, \mathrm{MeOH})$. Tetrahedron Asymmetry 2000, 11, 1593.

7) Methyl 3-amino-3-phenylpropanoate + methyl 3phenylpropanoate. Debenzylation was attempted on only one aryl PGA-enamine (3g). This PGA-amine $(50 \mathrm{mg})$ was dissolved in toluene $(2 \mathrm{~mL})$, acetic acid $(25 \mu \mathrm{L})$ and $7.5 \% \mathrm{Pd}(\mathrm{OH})_{2} / \mathrm{C}(40 \mathrm{mg})$ were added, and the mixture was stirred overnight at $50{ }^{\circ} \mathrm{C}$ under 40 psig of $\mathrm{H}_{2}$. The reaction mixture contained a trace of unconverted $\mathbf{3 g}$, 2-phenylacetamide byproduct, and a mixture of the two products, the

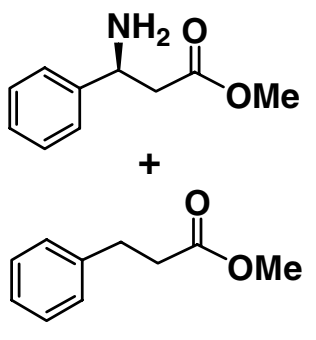
$\beta$-aminoester and over-reduced phenylpropanoate in 1:1.3 ratio.

Note: Thus, under hydrogenolysis conditions, the removal of the PGA group appears to be problematic with 3-arylpropanoates due to the presence of competing benzylic sites for hydrogenolysis. The degree of over-reduction should be less severe with electrondeficient 3-arylpropanoates such as $\mathbf{3 i}$ and heterocyclic compounds such as 3-pyridyl propanoates that can be protonated. 